\title{
EVALUATION OF THE INTERACTION EFFICIENCY BETWEEN ECO-ENVIRONMENT AND ECONOMIC DEVELOPMENT IN CHINA
}

\author{
CAO, L. ${ }^{1,2}-$ MA, Z. X. ${ }^{3}-$ MUREN $^{4,5^{*}}-$ CUI, W. ${ }^{4}-$ SIQIN $^{1}$ \\ ${ }^{1}$ School of Mathematics Science, Inner Mongolia University, Hohhot 010021, China \\ ${ }^{2}$ College of Computer and Information, Inner Mongolia Medical University, Hohhot 010110, \\ China \\ ${ }^{3}$ School of Economics and Management, Inner Mongolia University, Hohhot 010021, China \\ ${ }^{4}$ Inner Mongolia University of Technology, Hohhot 010051, China \\ ${ }^{5}$ Key Laboratory of Rail Transit, Beijing Jiaotong University, Beijing 100044, China \\ *Corresponding author \\ e-mail: muren@imut.edu.cn; phone:+86-185-8601-0847 \\ (Received $3^{\text {rd }}$ Apr 2019; accepted $17^{\text {th }}$ May 2019)
}

\begin{abstract}
The protection of eco-environment is the basis of economic development. It is the interaction between eco-environment and economic development that promotes the development of human society. Therefore, it is important to obtain relevant data and select an appropriate evaluation method to find out how these two are interacting with each other. In this paper, a new data envelopment analysis (DEA) model based on generalized DEA method and the multi-level index synthesis method is proposed for the first time to evaluate the interaction efficiency between eco-environment and economic development in Chinese provinces. Through correlation analysis of the indices, a scientific index system is established. After index synthesis, the new order of efficient provinces is established, and the improvement information for inefficient provinces has also been obtained. In addition, more scientific suggestions are put forward for the protection of eco-environment and economic development in China.
\end{abstract}

Keywords: multi-objective decision making, efficiency, generalized DEA, index synthesis, partial ordered relation

\section{Introduction}

No economic activity of mankind can be carried out without using nature resources, such as land, trees, water and so on (Brown, 2000). A well-protected eco-environment can provide continuous, high-quality and large amounts of resources for the sustainable economic development (Gaspar et al., 2017); on the other hand, a poorly-protected ecoenvironment will affect the stability and speed of economic development. Therefore, protection of eco-environment is the foundation of economic development. At the same time, economic development plays a decisive role in the virtuous cycle of ecoenvironment. No doubt, the economic development can cause damages to the ecoenvironment, especially the high-consumption, high-pollution and low-output production modes, which result in soil erosion, serious desertification and water and air pollution. However, the rapid economic development can also provide financial support for the protection and improvement of eco-environment, so as to maintain its healthy development. 
Many developed countries used to promote the rapid economic development at the expense of the environment (Mittler and Knirsch, 2007). China also had a similar experience. As a developing country, it has maintained its economic growth rate above $8 \%$, and even achieved a growth of $14 \%$ from 2000 to 2012, as shown in Figure 1, but this has been at the cost of environment to varying degrees. The smog in Beijing, the desertification in Inner Mongolia and the floods in the South are all clear evidence.

At present, the Chinese government has realized the importance of eco-environment protection (Zhou, 2015). It no longer blindly pursues rapid economic growth, but pays more attention to the sustainable development of both the environment and the economy. As a result, the GDP growth rate in China began to decline from 2013 to 2017, and the magnitude was the highest among the top five economies of the world. From the perspective of GDP, GDP and per capita GDP have been rising steadily on the whole, as shown in Figure 2.

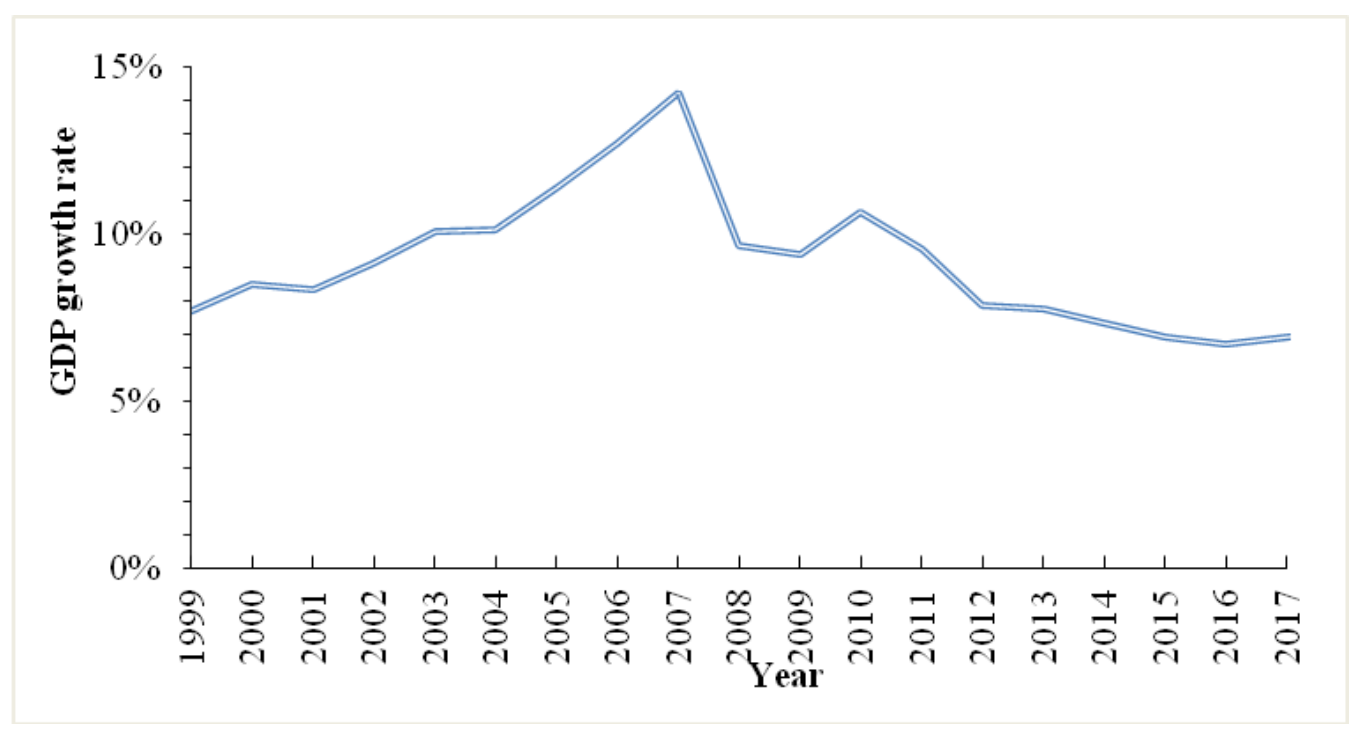

Figure 1. GDP growth rate from 1999 to 2017 in China

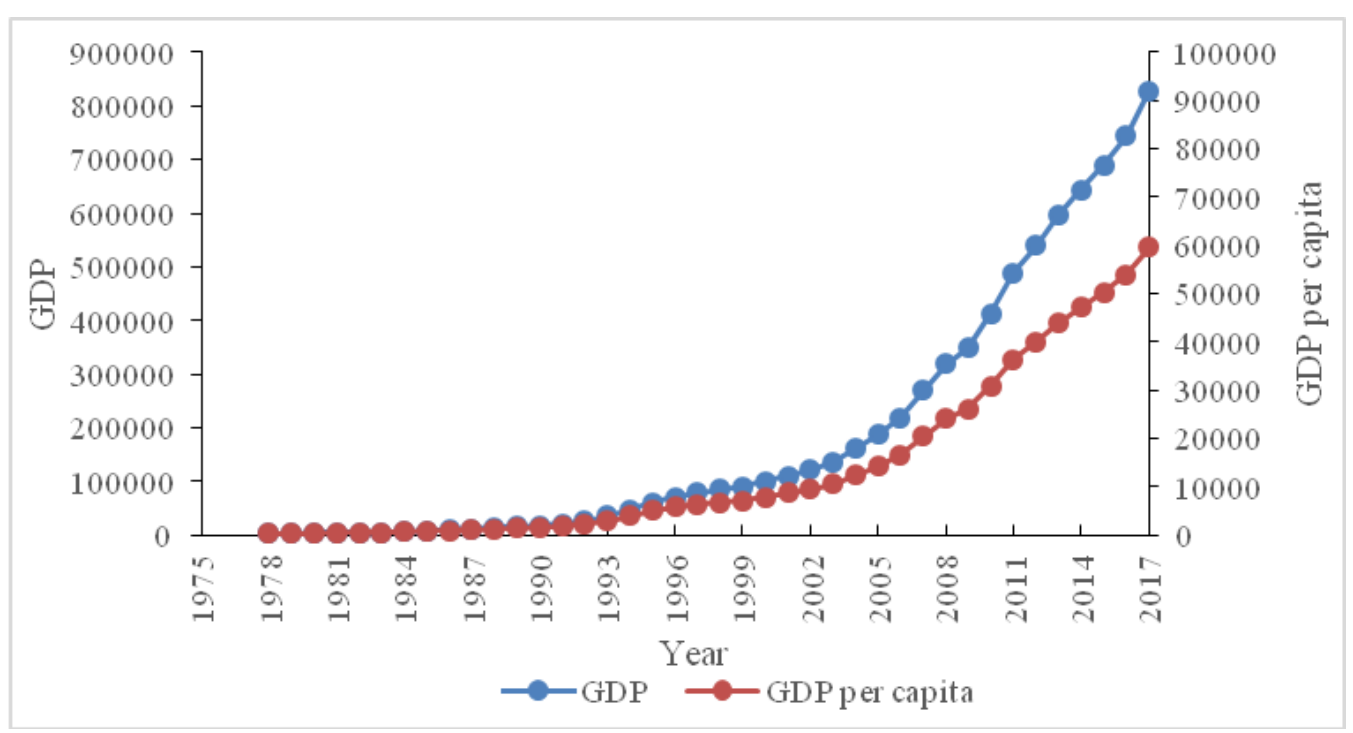

Figure 2. GDP and GDP per capita from 1978 to 2017 in China 
We can see that the shares of the primary and secondary industries, i.e., agriculture and manufacturing, in the national economy continue to decrease, whereas that of the tertiary industry continues to expand, as shown in Figure 3. In 2017, for example, the services industry accounted for 52.2 percent of China's GDP, up by 0.3 percent, while agriculture accounted for 7.1 percent and manufacturing 40.7 percent in China. Although the share of the secondary industry has declined, it still accounts for $40.7 \%$. Without strict protection of the eco-environment, it will cause great damages. Take Inner Mongolia for example, the share of the primary industry declined significantly, that of the secondary industry rose first and then declined, and that of the tertiary industry was relatively stable on the whole, but it rose after 2011, as shown in Figure 4. It can be said that the environment of Inner Mongolia was greatly affected by the industrial structure until after 2011.

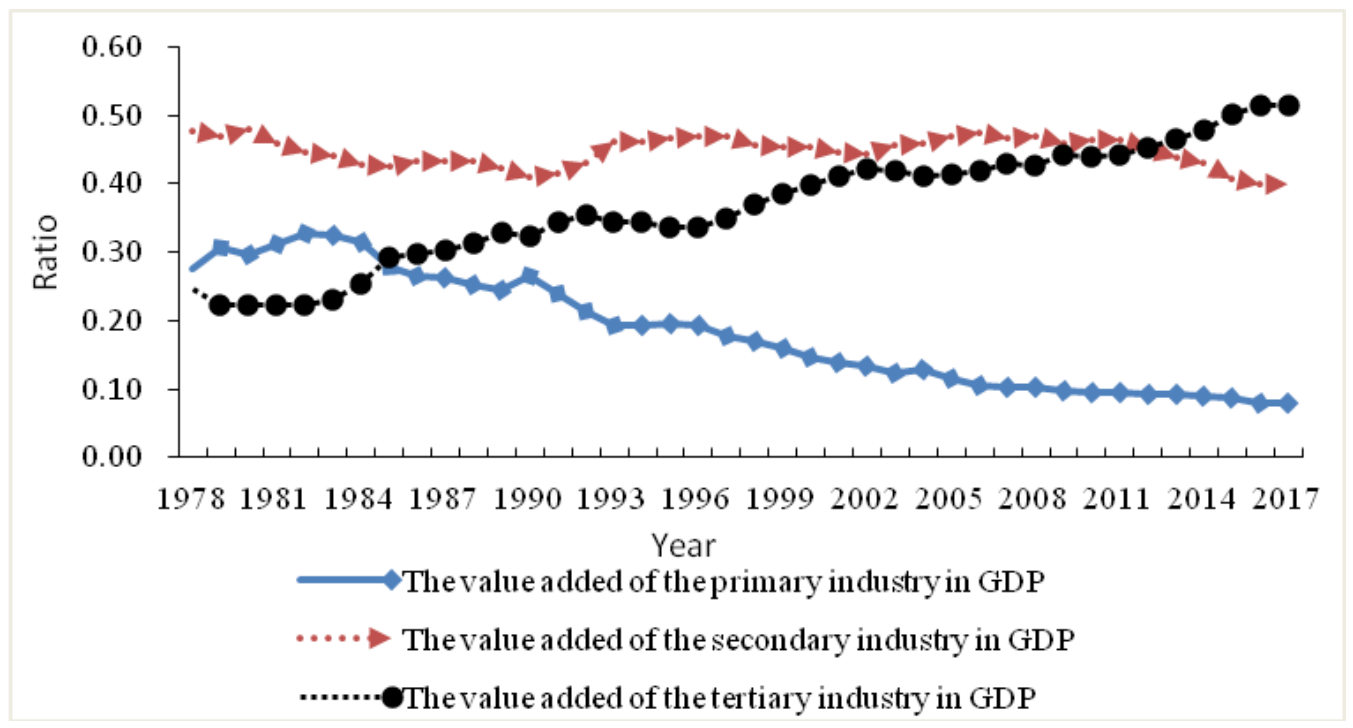

Figure 3. Primary, secondary and tertiary industries in GDP from 1978 to 2017 in China

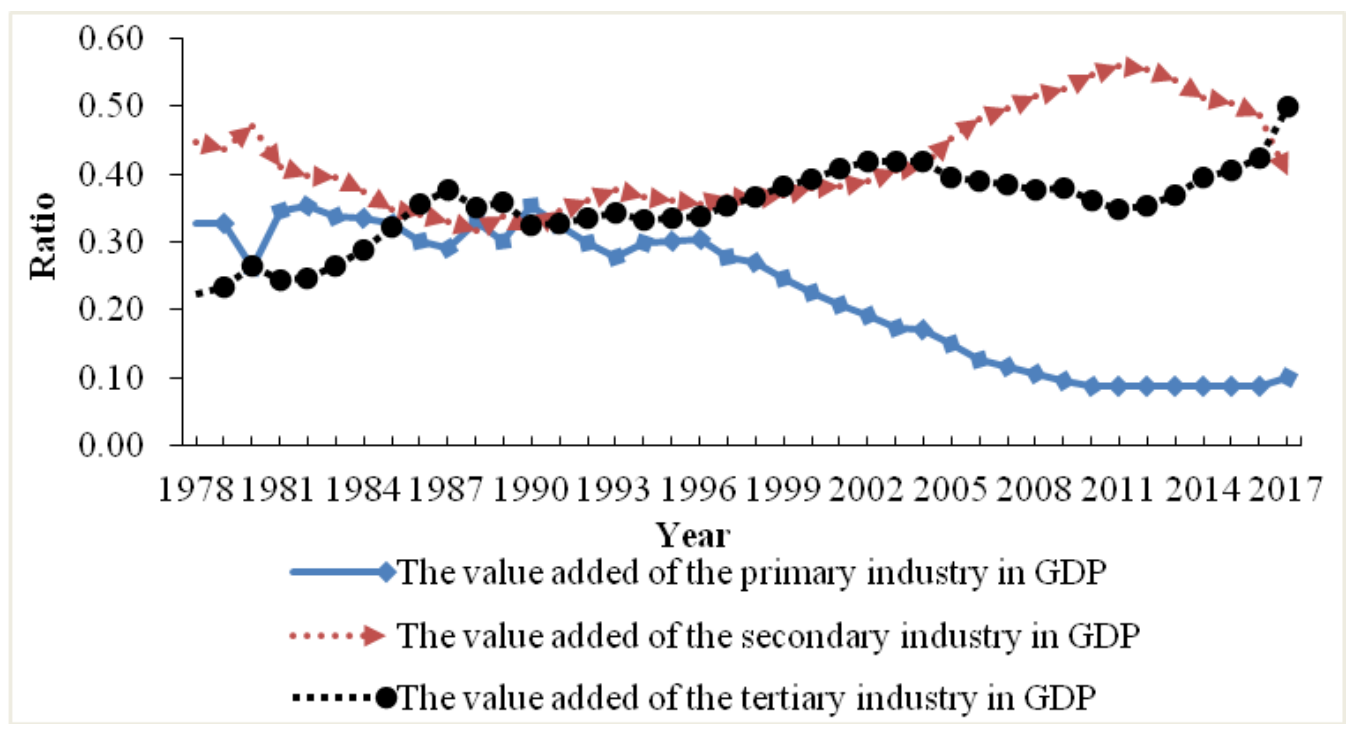

Figure 4. Primary, secondary and tertiary industries in GDP from 1978 to 2017 in Inner Mongolia 
As discussed above, China has gone through the process of developing economy at the expense of environment. Although in recent years, China has made great achievements in eco-environmental protection and at the same time successfully accomplished the targets set in the $13^{\text {th }}$ five-year plan (2016-2020), as reported at the Second Session of the $13^{\text {th }}$ National People's Congress, there is still much work to do due to the seriousness of the previous damages.

The interaction between eco-environment and economic development promotes the development of human society (Diao et al., 2009). So finding out how these two are interacting with each other using relevant data and appropriate methods has become a hot research topic. Most of the existing studies discussed how to maximize economic development with the minimum eco-environment damage based on the input-output efficiency. This idea is consistent with the theory of the data envelopment analysis (DEA) method (Banker et al., 1984; Charnes et al., 1978; Färe and Frosskopf, 1985; Seiford and Thrall, 1990). So the DEA method has been widely used in the ecoenvironment and economic efficiency analysis in recent years. For example, Moutinho et al. (2017) analyzed the economic and environmental efficiency assessment in EU cross-country based on DEA and the quantile regression approach. Mavi et al. (2018) applied a two-stage network DEA method based on goal programming to analyze the joint effects of eco-environment and eco-innovation on the countries in the Organization for Economic Co-operation and Development (OECD). Halkos et al. (2018) estimated the efficiency of the power generation sector in the USA by using window DEA (WDEA) to model the relationships between environmental efficiency and economic growth. Moutinho et al. (2018) analyzed the performances of a number of German and French cities using the DEA technique. Song et al. (2018) conducted DEA to evaluate the environmental efficiency of Chinese regions. It should be emphasized that there have been many studies on the efficiency evaluation of the eco-environment and economic development in China in recent years. These studies can be summarized as follows: (1) The traditional DEA model is directly used for evaluation, and for example, Jia and Liu used the input-oriented BCC-type DEA models to calculate energy and environment efficiency of 30 provinces in China (2012), and some papers discussed environment efficiency based on the DEA-SBM model (Chang et al., 2014; Ma et al., 2017; Yang et al., 2012); (2) the traditional DEA method is combined with other methods (Lee et al., 2013); and (3) the traditional DEA model is improved, and for example, Liu et al. (2018) brought forward an ideal point cross efficiency (IPCE) model to avoid the disadvantage of the 'self-evaluation' method and analyzed the carbon emissions efficiency of 10 typical urban agglomerations from 2008 to 2015 in China, and Wang and Wu (2014) proposed a new two-stage multiplier DEA approach to evaluate the environmental and economic performance of 30 provinces and municipalities in China.

Since the eco-environment system and economic system are complex systems, many indices in the eco-environment system are likely to affect economic development. How many indices are selected in the research will bring different efficiency evaluation results. At present, most of the studies use only a small number of indices to evaluate the eco-environment and economic development efficiency. But that does not mean the number of selected indices can be excessively large, because in that case, the majority of DMUs will be regarded as efficient when the DEA method is applied to the evaluation, which is useless to the decision makers. 
DEA is particularly applicable to the analysis of complex systems such asecoenvironment and economy systems. However, the DEA method also has some disadvantages that cannot be overcome because of the complexity of the systems. Firstly, the evaluation result may over-emphasize the role of secondary indices. Secondly, it often appears that most DMUs are efficient. Thirdly, it has high requirements on projection. Fourthly, it cannot determine how to improve the original indices after the synthetic of indices.

In order to solve the above problems, this paper applies the generalized DEA method and the multi-level index synthesis technique for the first time to evaluate the interaction efficiency between eco-environment and economic development. The generalized DEA proposed is based on sample evaluation (Ma et al., 2002, 2003, 2012, 2018). The evaluation reference set is not limited to the optimal criteria. For example, the admission line for college entrance examination reflects the average level, and the bottom line in wind risk analysis reflects the minimum evaluation criteria. Of course, sometimes the evaluation criteria may be specific units, such as selected templates, standards or certain objects. Such problems cannot be solved by the traditional DEA. The multi-level index synthesis technique can not only obtain the ranking of DMUs, but also solve the ranking problem that most DMUs are efficient, and obtain the improved information of the original index (Muren et al., 2013).

\section{Materials and methods}

\section{Multi-level index synthesis method}

Suppose that there are $n$ DMUs. $x_{i j}^{(l)}$ denotes the value of the $l$ th lower index of the $i$ th input index of the $j$ th DMU, $y_{r j}^{(t)}$ denotes the value of the $t$ th lower index of the $r$ th input index of the $j$ th DMU, and $x_{i j}^{(l)}$ and $y_{r j}^{(t)}$ are both positive. Suppose there is another $\bar{n}$ sample DMUs as the reference sample for evaluation. $\bar{x}_{i j}^{(l)}$ denotes the value of the $l$ th lower index of the $i$ th input index of the $j$ th sample DMU, $\bar{y}_{r j}^{(t)}$ denotes the value of the $t$ th lower index of the $r$ th input index of the $j$ th sample DMU, and $\bar{x}_{i j}^{(l)}$ and $\bar{y}_{r j}^{(t)}$ are both positive. The input-oriented synthesis model based on generalized DEA is represented as follows when the $p$ th DMU is evaluated, where $1 \leq p \leq n$.

$$
(\text { IGDEA })\left\{\begin{array}{l}
\min \theta-\varepsilon\left(\sum_{i=1}^{m} \sum_{l=1}^{L_{i}} a_{i}^{l} s_{i}^{l-}+\sum_{r=1}^{s} \sum_{t=1}^{T_{r}} b_{r}^{t} s_{r}^{t+}\right) \\
\text { s.t. } \quad \sum_{j=1}^{\bar{n}} \bar{x}_{i j}^{(l)} \lambda_{j}+s_{i}^{l-}=\theta x_{i p}^{(l)}, \quad l=1,2, \cdots, L_{i}, \quad i=1,2, \cdots, m \\
\sum_{j=1}^{\bar{n}} \bar{y}_{r j}^{(t)} \lambda_{j}-s_{r}^{t+}=y_{r p}^{(t)}, \quad t=1,2, \cdots, T_{r} \quad r=1,2, \cdots, s \\
\\
\delta_{1}\left(\sum_{j=1}^{\bar{n}} \lambda_{j}-\delta_{2}(-1)^{\delta_{3}} \lambda_{\bar{n}+1}\right)=\delta_{1} \\
\\
\sum_{l=1}^{L_{i}} a_{i}^{l} s_{i}^{l-} \geq 0, i=1,2, \cdots, m, \\
\sum_{t=1}^{T_{r}} b_{r}^{t} s_{r}^{t+} \geq 0, \quad r=1,2, \cdots, s \\
\lambda_{j} \geq 0, \quad j=1,2, \cdots, \bar{n}+1
\end{array}\right.
$$


where:

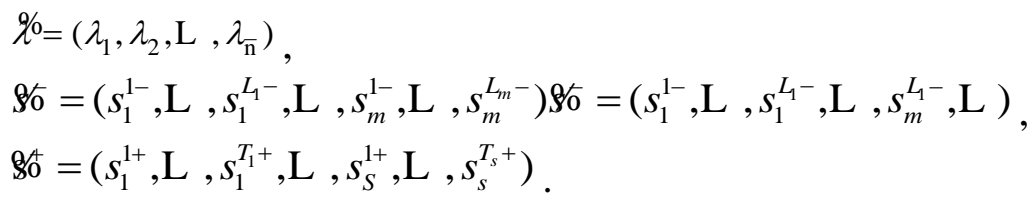

Definition 1 Assuming that $\theta^{0}, \ell^{6}, \lambda_{\bar{n}+1}^{0}, \$ 0^{0}, 30^{0}$ is the optimal solution of model Equation 1, we can call DMUp is IG-DEA efficient if it meets one of the following conditions,

(1) $\theta^{0}=1, \sum_{l=1}^{L_{i}} a_{i}^{l} s_{i}^{l-0}=0, i=1,2, \mathrm{~L}, m$, and $\sum_{t=1}^{T_{\mathrm{r}}} b_{r}^{t} s_{r}^{t+0}=0, r=1,2, \mathrm{~L} s$;

(2) $\theta^{0}>1$;

(3) Model (1) has no feasible solution.

Definition 2 Assuming that $\theta^{0}, \ell^{2}, \lambda_{\bar{n}+1}^{0}, 90^{0}, \xi 0^{0}$ is the optimal solution of model Equation 1, let $\ell_{i p}^{(l)}=\theta^{0} x_{i p}^{(l)}-s_{i}^{l-0}, \oint_{i p}^{(t)}=y_{r p}^{(t)}+s_{r}^{t+0}, l=1,2, \mathrm{~L}, L_{i}, i=1,2, \mathrm{~L}, m, t=1,2, \mathrm{~L}, T_{r}$, $r=1,2, \mathrm{~L}, s$ and the projection of DMUp on the effective surface of the sample is expressed as $\left(\left(\tilde{x}_{1 p}^{(1)}, \ldots, \tilde{x}_{1 p}^{\left(L_{1}\right)}, \ldots, \tilde{x}_{m p}^{(1)}, \ldots, \tilde{x}_{m p}^{\left(L_{m}\right)}\right),\left(\tilde{y}_{1 p}^{(1)}, \ldots, \tilde{y}_{1 p}^{\left(T_{1}\right)}, \ldots, \tilde{y}_{s p}^{(1)}, \ldots, \tilde{y}_{s p}^{\left(T_{s}\right)}\right)\right)$.

However, in many practical evaluation problems, input is often constant. In this case, the DMU can only be improved by increasing the output. Therefore, the study on the output-oriented efficiency evaluation model is equally important. The output-oriented synthesis model based on generalized DEA is represented in model Equation 2.

$$
(\text { OGDEA })\left\{\begin{array}{l}
\max \varphi+\varepsilon\left(\sum_{i=1}^{m} \sum_{l=1}^{L_{i}} a_{i}^{l} s_{i}^{l-}+\sum_{r=1}^{s} \sum_{t=1}^{T_{r}} b_{r}^{t} s_{r}^{t+}\right) \\
\text { s.t. } \quad \sum_{j=1}^{n} x_{i j}^{(l)} \lambda_{j}+s_{i}^{l-}=x_{i j_{0}}^{(l)}, \quad l=1,2, \cdots, L_{i}, \quad i=1,2, \cdots, m \\
\sum_{j=1}^{n} \bar{y}_{r j}^{(t)} \lambda_{j}-s_{r}^{t+}=\varphi y_{r j_{0}}^{(t)}, \quad t=1,2, \cdots, T_{r} r=1,2, \cdots, s \\
\delta_{1}\left(\sum_{j=1}^{n} \lambda_{j}-\delta_{2}(-1)^{\delta_{3}} \lambda_{n+1}\right)=\delta_{1} \\
\sum_{l=1}^{L_{i}} a_{i}^{l} s_{i}^{l-} \geq 0, i=1,2, \cdots, m \\
\sum_{t=1}^{T_{r}} b_{r}^{t} s_{r}^{t+} \geq 0, \quad r=1,2, \cdots, s \\
\lambda_{j} \geq 0, \quad j=1,2, \cdots, n+1
\end{array}\right.
$$

Definition 3 Assuming that $\varphi^{0}, \lambda^{0}, \lambda_{n+1}^{0}, 30^{0}, \$ 0^{0}$ is the optimal solution of model Equation 2 and $\varphi^{0}=1 \sum_{l=1}^{L_{i}} a_{i}^{l} s_{i}^{l-0}=0, i=1,2, \cdots, m, \sum_{i=1}^{T_{r}} b_{r}^{t} s_{r}^{t+0}=0, r=1,2, \cdots, s$, and DMUp is call OG-DEA efficient. The efficiency of DMUp is expressed as $\frac{1}{\varphi^{0}}$.

Definition4 Assuming that $\varphi^{0}, \lambda^{0}, \lambda_{n+1}^{0}, 30^{0}, \$ 0^{0}$ is the optimal solution of model Equation 2, let $\xi_{i j 0}^{t l)}=x_{i j 0}^{(l)}-s_{i}^{l-0}, \xi_{r j 0}^{t t}=\varphi^{0} y_{r j 0}^{(t)}+s_{r}^{t+0}, l=1,2, \mathrm{~L}, L_{i}, i=1,2, \mathrm{~L}, m, t=1,2, \mathrm{~L}, T_{r}, r=1,2, \mathrm{~L}, s$ 
and the projection of $\mathrm{DMU}_{j 0}$ on the effective surface of the sample is expressed as $\left(\left(\tilde{x}_{1 j_{0}}^{(1)}, \ldots, \tilde{x}_{1 j_{0}}^{\left(L_{1}\right)}, \ldots, \tilde{x}_{m j_{0}}^{(1)}, \ldots, \tilde{x}_{m_{j_{0}}}^{\left(L_{m}\right)}\right),\left(\tilde{y}_{1 j_{0}}^{(1)}, \ldots, \tilde{y}_{1_{j_{0}}}^{\left(T_{1}\right)}, \ldots, \tilde{y}_{s_{0}}^{(1)}, \ldots, \tilde{y}_{s_{j}}^{\left(T_{s}\right)}\right)\right)$.

\section{Selection of environmental and economic indices}

There are many indices to evaluate the degree of eco-environment damages and the level of pollution. In the Statistical Yearbook of China, there are 21 sub-indices under the index of resource and environment, and there are further sub-indices under each sub-index. Taking the index of 'Collection, Transport and Disposal of Urban Consumption Wastes' for example, there are 16 sub-indices under it. The sub-indices under the resource and environment index are not only numerous, but also have complex relations among them, including certain degree of correlation.

Through review of relevant documents, it is found that the main pollutants in waste water and the main pollutants in waste gas are mainly selected by researchers in the evaluation on the environments of various provinces in China. In fact, for a country with a high urbanization level, municipal solid waste (MSW) has also become an important index to the environment. Therefore, this paper decides to adopt the above three environmental indices to evaluate the environmental status and analyze the impact on the economy of every province in China.

In order to reflect these environmental indices more accurately, this paper digs into the sub-indices of the above three indices. The results show that there are strong correlations between these indices. If all the sub-indices are selected as input indices, it will be difficult to distinguish the main differences in environmental status among the provinces by the DEA method because of the data correlation. Therefore, scientific selection and combination of these indices is an important prerequisite for better evaluation of environmental status.

For the 14 sub-indices under the index 'Discharge of Main Pollutants in Waste Water', this paper removes the indices with relatively small discharges and low correlation with the main index, and then selects the typical indices with high correlations. Finally, the sub-indices selected are 'Total Waste Water Discharged', 'Petroleum Discharge in Waste Water', and 'Plumbum Discharge in Waste Water'.

For the 3 sub-indices under the index 'Emission of Main Pollutants in Waste Gas', the correlation between them is between 0.7 and 0.8 , and the difference between the data is not obvious, so three sub-indices are all selected, namely 'Sulphur Dioxide Emission in Waste Gas', 'Nitrogen Oxides Emission in Waste Gas' and 'Smoke and Dust Emission in Waste Gas'.

For the 11 sub-indices under the index 'Collection, Transport and Disposal of Urban Consumption Wastes', only two sub-indices are selected, namely 'Volume of Garbage Disposal' and 'Treatment Rate of Consumption Wastes', because there is no significant correlation between them, but strong correlation between the other indices and the index of 'Volume of Garbage Disposal'.

Many economic and social activities have had significant impacts on the ecoenvironment. Some of the most important economic indices are selected, which are 'Gross Regional Product', 'Local Government's Expenditure', 'Local Government's Revenue', and 'Income and Consumption Expenditure by Nationwide, Urban and Rural Households'.

For the 14 sub-indices under the index 'Regional Gross Product', the correlation between the 2 sub-indices 'Gross Regional Product' and 'Per Capita Gross Regional 
Product' is weak, but all other sub-indices have strong correlations with 'Gross Regional Product'. Therefore, only the two sub-indices 'Gross Regional Product' and 'Per Capita Gross Regional Product' are selected.

For the 22 sub-indices under the index 'Local Governments Revenue', since all subindices are counted in big numbers, some smaller sub-indices are eliminated. There are strong correlations between all the remaining sub-indices and the sub-index 'Local Governments General Budgetary Revenue', so the latter is selected. For the 21 indices under 'Local Governments Expenditure', only the 'Local Governments General Budgetary Expenditure' index is selected.

For the 6 sub-indices under the index 'Income and Consumption Expenditure by Nationwide, Urban and Rural Households (new caliber)', all have strong correlations with 'Per Capita Disposable Income Nationwide', so only the latter is selected.

\section{Evaluation index system}

Through the above-mentioned index selection, the following index system is established to evaluate the eco-environmental situation in the provinces of China, as shown in Figure 5.

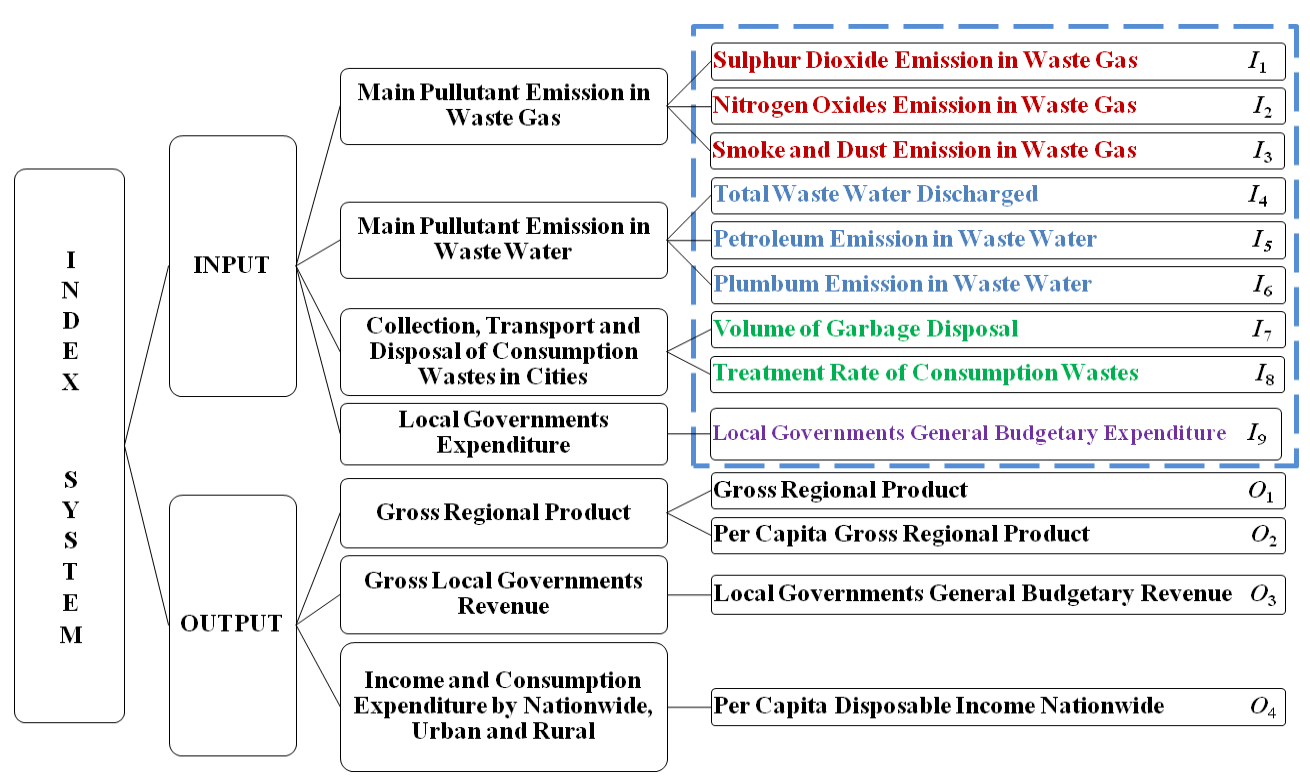

Figure 5. Index system structure

\section{Results and discussion}

\section{Environment-economy interaction efficiency of Chinese provinces in 2017}

There are some differences in the dimensions of data, which can easily lead to errors in the calculation results. Therefore, this paper puts all the input-output indices between 0.1 and 1 through the following normalization formulas.

$$
x_{i j}=0.1+\frac{0.9\left(x_{i j}-\min _{1 \leq \leq n} x_{i j}\right)}{\max _{1 \leq j \leq n} x_{i j}-\min _{1 \leq j \leq n} x_{i j}} \quad i=1,2, \cdots, 9, j=1,2, \cdots, 31
$$




$$
y_{k j}=0.1+\frac{0.9\left(y_{k j}-\min _{1 \leq j \leq n} y_{k j}\right)}{\max _{1 \leq j \leq n} y_{k j}-\min _{1 \leq j \leq n} y_{k j}} \quad k=1,2,3,4, j=1,2, \cdots, 31
$$

After normalization, the efficiency values of 31 provinces in the CCR model and the BCC model are calculated using the software MATLAB. The results are shown in Table 1.

From Table 1, it can be seen that 16 provinces are efficient and 15 other provinces are inefficient in the BCC model before index synthesis. The order is as follows: Beijing, Fujian, Guangdong, Hainan, Heilongjiang, Jiangsu, Jilin, Ningxia, Qinghai, Shaanxi, Shandong, Shanghai, Tianjin, Tibet, Yunnan, Zhejiang > Liaoning > Chongqing $>$ Henan $>$ Guangxi $>$ Shanxi $>$ Hebei $>$ Xinjiang $>$ Hubei $>$ Sichuan $>$ Jiangxi > Inner Mongolia > Guizhou > Hunan > Anhui > Gansu. After index synthesis, the results obtained by the $\mathrm{BCC}$ model show that 13 provinces are efficient and 18 provinces are inefficient. The order of efficiency is as follows: Beijing, Fujian, Guangdong, Hainan, Heilongjiang, Jiangsu, Jilin, Ningxia, Qinghai, Shanghai, Tianjin, Tibet, Zhejiang $>$ Shandong $>$ Shanxi $>$ Henan $>$ Xinjiang $>$ Chongqing $>$ Hebei $>$ Shaanxi > Guizhou > Hunan > Sichuan > Guangxi > Liaoning > Anhui > Inner Mongolia > Jiangxi > Gansu > Yunnan, in which a new order for Shaanxi, Shandong and Yunnan is obtained.

Table 1. Results of eco-environmental evaluation in China in 2017

\begin{tabular}{|c|c|c|c|c|c|c|c|c|c|}
\hline \multirow[b]{2}{*}{ Province } & \multicolumn{2}{|c|}{ CCR } & \multicolumn{2}{|c|}{ BCC } & \multirow[b]{2}{*}{ Province } & \multicolumn{2}{|c|}{ CCR } & \multicolumn{2}{|c|}{ BCC } \\
\hline & $\begin{array}{c}\text { Original } \\
\text { index }\end{array}$ & $\begin{array}{c}\text { Synthesized } \\
\text { index }\end{array}$ & $\begin{array}{c}\text { Original } \\
\text { index }\end{array}$ & $\begin{array}{c}\text { Synthesized } \\
\text { index }\end{array}$ & & $\begin{array}{c}\text { Original } \\
\text { index }\end{array}$ & $\begin{array}{l}\text { Synthesized } \\
\text { index }\end{array}$ & $\begin{array}{c}\text { Original } \\
\text { index }\end{array}$ & $\begin{array}{c}\text { Synthesized } \\
\text { index }\end{array}$ \\
\hline Beijing & 1.0000 & 1.0000 & 1.0000 & 1.0000 & Hubei & 0.8810 & 0.7715 & 0.8982 & 0.8419 \\
\hline Tianjin & 1.0000 & 1.0000 & 1.0000 & 1.0000 & Hunan & 0.8814 & 0.7378 & 0.8817 & 0.8148 \\
\hline Hebei & 0.9297 & 0.7243 & 0.9315 & 0.8452 & Guangdong & 1.0000 & 1.0000 & 1.0000 & 1.0000 \\
\hline Shanxi & 0.7951 & 0.7927 & 0.9513 & 0.9089 & Guangxi & 0.8768 & 0.6180 & 0.9521 & 0.8014 \\
\hline Inner Mongolia & 0.8521 & 0.6343 & 0.8865 & 0.7390 & Hainan & 1.0000 & 1.0000 & 1.0000 & 1.0000 \\
\hline Liaoning & 0.7677 & 0.7535 & 0.9853 & 0.7864 & Chongqing & 0.8391 & 0.7900 & 0.9670 & 0.8587 \\
\hline Jilin & 1.0000 & 1.0000 & 1.0000 & 1.0000 & Sichuan & 0.8267 & 0.6634 & 0.8951 & 0.8065 \\
\hline Heilongjiang & 0.7368 & 0.6891 & 1.0000 & 1.0000 & Guizhou & 0.7917 & 0.6065 & 0.8846 & 0.8199 \\
\hline Shanghai & 1.0000 & 1.0000 & 1.0000 & 1.0000 & Yunnan & 0.9267 & 0.5541 & 1.0000 & 0.6608 \\
\hline Jiangsu & 1.0000 & 1.0000 & 1.0000 & 1.0000 & Tibet & 0.8140 & 0.7021 & 1.0000 & 1.0000 \\
\hline Zhejiang & 1.0000 & 1.0000 & 1.0000 & 1.0000 & Shaanxi & 1.0000 & 0.7067 & 1.0000 & 0.8414 \\
\hline Anhui & 0.8533 & 0.6759 & 0.8557 & 0.7843 & Gansu & 0.7009 & 0.5639 & 0.8484 & 0.7233 \\
\hline Fujian & 1.0000 & 0.9987 & 1.0000 & 1.0000 & Qinghai & 0.8117 & 0.8068 & 1.0000 & 1.0000 \\
\hline Jiangxi & 0.8576 & 0.6769 & 0.8888 & 0.7328 & Ningxia & 0.9689 & 0.9689 & 1.0000 & 1.0000 \\
\hline Shandong & 1.0000 & 0.9843 & 1.0000 & 0.9862 & Xinjiang & 0.6992 & 0.5700 & 0.9252 & 0.8706 \\
\hline Henan & 0.9337 & 0.7948 & 0.9636 & 0.8903 & & & & & \\
\hline
\end{tabular}

It is known from Table 1 that the efficiency values of some provinces have changed significantly after index synthesis. Some of the efficient provinces have become inefficient, such as Shandong, whose efficiency drops to 0.9843 in the CCR model and 0.9862 in the BCC model in 2017, and Yunnan, whose efficiency drops to 0.6608 in the BCC model in 2017 and so on. In the BCC model, the number of efficient provinces decreases from 16 to 13 after index synthesis. To some extent, it shows that the environmental status of these provinces is below the desired level, and only by enlargement of their advantages, can they become efficient. In fact, the evaluation 
results after index synthesis are more reasonable, because they have considered the environmental indices of each province comprehensively.

The projection information of the DMUs on the production frontier will become the projection information of the composite indices after index synthesis. Thus, the improvement of the original input indices of each province and the results of the total improvement ranking are given in Table 2 by using the relevant theories proposed in the section of Materials and Methods. The input-oriented projection improvement information of Chinese provinces in the BCC model under the assumption of variable returns to scale (VRS) is shown in Table 2.

From Table 2, the following conclusions can be drawn. First, the table shows how the all original indices are improved and the total improvement of each province. There are three provinces with total improvement being more than $75 \%$, which are Hebei, Inner Mongolia and Liaoning. Second, there are three provinces which become inefficient after index synthesis, namely Shandong, Yunnan and Shaanxi. It can be seen that they still have shortcomings. For example, Shandong has a total improvement of $38.22 \%$, with the sulphur dioxide emission, nitrogen oxides emission and smoke and dust emission in waste gas being more than $9 \%$ redundant. Other indices also have a small amount of redundancy. Finally, the calculation results in Table 2 show that the model can not only identify high system efficiency, but also discover more inefficient information in systems and provide the improvement of all the indices.

Table 2. Input-oriented projection improvement information of the provinces in the BCC model under the assumption of VRS

\begin{tabular}{c|c|c|c|c|c|c|c|c|c|c}
\hline & $\mathbf{I}$ & $\mathbf{I} 2$ & $\mathbf{I 3}$ & $\mathbf{I 4}$ & $\mathbf{I 5}$ & $\mathbf{I 6}$ & $\mathbf{I 7}$ & $\mathbf{I 8}$ & $\mathbf{I 9}$ & $\begin{array}{c}\text { Total } \\
\text { improvement }\end{array}$ \\
\hline Liaoning & $12.53 \%$ & $12.23 \%$ & $15.81 \%$ & $4.02 \%$ & $1.27 \%$ & $8.67 \%$ & $4.09 \%$ & $10.37 \%$ & $7.07 \%$ & $76.06 \%$ \\
Inner Mongolia & $17.36 \%$ & $10.88 \%$ & $15.86 \%$ & $1.74 \%$ & $3.27 \%$ & $3.12 \%$ & $2.76 \%$ & $12.80 \%$ & $8.04 \%$ & $75.83 \%$ \\
Hebei & $16.10 \%$ & $17.75 \%$ & $19.33 \%$ & $1.82 \%$ & $0.71 \%$ & $2.75 \%$ & $2.52 \%$ & $7.69 \%$ & $6.92 \%$ & $75.59 \%$ \\
Jiangxi & $4.82 \%$ & $4.82 \%$ & $5.47 \%$ & $4.67 \%$ & $15.01 \%$ & $6.36 \%$ & $3.21 \%$ & $12.34 \%$ & $9.25 \%$ & $65.95 \%$ \\
Yunnan & $7.43 \%$ & $3.81 \%$ & $4.54 \%$ & $3.56 \%$ & $12.58 \%$ & $2.18 \%$ & $3.83 \%$ & $13.01 \%$ & $13.09 \%$ & $64.03 \%$ \\
Shanxi & $18.77 \%$ & $11.58 \%$ & $13.71 \%$ & $0.70 \%$ & $0.33 \%$ & $0.93 \%$ & $1.14 \%$ & $3.81 \%$ & $2.34 \%$ & $53.31 \%$ \\
Xinjiang & $12.90 \%$ & $8.19 \%$ & $14.00 \%$ & $0.85 \%$ & $0.59 \%$ & $1.85 \%$ & $1.38 \%$ & $4.12 \%$ & $7.96 \%$ & $51.84 \%$ \\
Guizhou & $17.11 \%$ & $6.63 \%$ & $5.75 \%$ & $1.28 \%$ & $0.75 \%$ & $2.39 \%$ & $1.76 \%$ & $7.62 \%$ & $5.64 \%$ & $48.93 \%$ \\
Hunan & $2.21 \%$ & $2.26 \%$ & $2.02 \%$ & $4.87 \%$ & $5.44 \%$ & $8.54 \%$ & $3.23 \%$ & $9.20 \%$ & $8.56 \%$ & $46.33 \%$ \\
Anhui & $3.97 \%$ & $4.83 \%$ & $4.24 \%$ & $2.40 \%$ & $1.26 \%$ & $3.64 \%$ & $3.19 \%$ & $10.75 \%$ & $9.02 \%$ & $43.30 \%$ \\
Sichuan & $3.69 \%$ & $2.84 \%$ & $2.23 \%$ & $3.00 \%$ & $1.69 \%$ & $2.56 \%$ & $4.13 \%$ & $9.21 \%$ & $13.41 \%$ & $42.76 \%$ \\
Gansu & $4.72 \%$ & $2.81 \%$ & $3.35 \%$ & $1.47 \%$ & $4.62 \%$ & $2.21 \%$ & $2.38 \%$ & $13.13 \%$ & $6.29 \%$ & $40.98 \%$ \\
Shandong & $12.76 \%$ & $12.76 \%$ & $9.10 \%$ & $0.41 \%$ & $0.15 \%$ & $0.39 \%$ & $0.70 \%$ & $1.10 \%$ & $0.85 \%$ & $38.22 \%$ \\
Shaanxi & $4.68 \%$ & $3.71 \%$ & $3.85 \%$ & $1.45 \%$ & $1.03 \%$ & $1.97 \%$ & $1.71 \%$ & $7.68 \%$ & $5.20 \%$ & $31.28 \%$ \\
Guangxi & $2.07 \%$ & $2.33 \%$ & $2.18 \%$ & $1.96 \%$ & $1.75 \%$ & $1.48 \%$ & $2.34 \%$ & $9.90 \%$ & $6.61 \%$ & $30.62 \%$ \\
Hubei & $1.92 \%$ & $1.98 \%$ & $1.61 \%$ & $1.97 \%$ & $1.43 \%$ & $2.12 \%$ & $3.15 \%$ & $7.88 \%$ & $7.23 \%$ & $29.29 \%$ \\
Chongqing & $3.87 \%$ & $2.28 \%$ & $1.78 \%$ & $1.41 \%$ & $0.50 \%$ & $1.48 \%$ & $1.89 \%$ & $6.93 \%$ & $4.17 \%$ & $24.31 \%$ \\
Henan & $1.63 \%$ & $2.21 \%$ & $1.26 \%$ & $1.88 \%$ & $0.56 \%$ & $1.53 \%$ & $2.33 \%$ & $5.43 \%$ & $6.04 \%$ & $22.87 \%$ \\
\hline
\end{tabular}

\section{Environment-economy interaction efficiency of Chinese provinces from 2013 to 2017}

Due to the fluctuation and differences of economic development and environmental status in different provinces in different years, it is not enough to use only one year's 
data to evaluate the overall situation of each province. To this end, this paper uses the input-output data of Chinese provinces from 2013 to 2017.

Based on the average input and output data of Chinese provinces from 2013 to 2017, the sample DMUs of each province are provided. Then the environmental evaluation results of each province are proposed, as shown in Table 3.

From Table 3, the following conclusions can be drawn. First, there are 16 provinces are efficient and 15 other provinces are inefficient in the BCC model before index synthesis. The order is as follows: Beijing, Tianjin, Liaoning, Jilin, Heilongjiang, Shanghai, Jiangsu, Zhejiang, Fujian, Shandong, Guangdong, Hainan, Tibet, Gansu, Qinghai, Ningxia > Chongqing > Xinjiang > Hebei > Inner Mongolia > Guizhou > Shanxi $>$ Hubei $>$ Hunan $>$ Henan $>$ Jiangxi $>$ Sichuan $>$ Anhui $>$ Yunnan $>$ Guangxi $>$ Shaanxi. Second, after index synthesis, it is not difficult to find that the efficiency values of some provinces have changed significantly. Some of these efficient provinces have become inefficient, such as Liaoning, whose efficiency drops to 0.8365 in the BCC model. The new order of these provinces is obtained as follows: Beijing, Tianjin, Jilin, Heilongjiang, Shanghai, Jiangsu, Zhejiang, Fujian, Shandong, Guangdong, Hainan, Tibet, Gansu, Qinghai, Ningxia > Hebei > Liaoning > Shanxi > Hunan > Xinjiang > Henan > Chongqing > Sichuan > Guangxi > Guizhou > Jiangxi > Inner Mongolia > Shaanxi $>$ Anhui $>$ Yunnan. From this, it can be seen that the most of the provinces with high efficiency are located in the east region, and the average efficiency of the east region is the highest. The average efficiency of the central region is similar to that of the western region, but the most of the provinces with low efficiency are located in the west region.

Table 3. Results of environment-economy interaction efficiency in Chinese provinces from 2013 to 2017 based on the generalized DEA method

\begin{tabular}{c|c|c|c|c|c|c|c|c|c}
\hline \multirow{2}{*}{ Province } & \multicolumn{2}{|c|}{ CCR } & \multicolumn{2}{c|}{ BCC } & & \multicolumn{2}{c|}{ CCR } & \multicolumn{2}{c}{ BCC } \\
\cline { 2 - 4 } \cline { 7 - 9 } & $\begin{array}{c}\text { Original } \\
\text { index }\end{array}$ & $\begin{array}{c}\text { Synthesized } \\
\text { index }\end{array}$ & $\begin{array}{c}\text { Original } \\
\text { index }\end{array}$ & $\begin{array}{c}\text { Synthesized } \\
\text { index }\end{array}$ & Province & $\begin{array}{c}\text { Original } \\
\text { index }\end{array}$ & $\begin{array}{c}\text { Synthesized } \\
\text { index }\end{array}$ & $\begin{array}{c}\text { Original } \\
\text { index }\end{array}$ & $\begin{array}{c}\text { Synthesized } \\
\text { index }\end{array}$ \\
\hline Beijing & 1.0000 & 1.0000 & 1.0000 & 1.0000 & Hubei & 0.8468 & 0.7731 & 0.9133 & 0.8722 \\
Tianjin & 1.0000 & 1.0000 & 1.0000 & 1.0000 & Hunan & 0.8754 & 0.7512 & 0.8863 & 0.8304 \\
Hebei & 0.8991 & 0.7977 & 0.9739 & 0.8695 & Guangdong & 1.0000 & 1.0000 & 1.0000 & 1.0000 \\
Shanxi & 0.7622 & 0.7605 & 0.9218 & 0.8344 & Guangxi & 0.7992 & 0.6857 & 0.8352 & 0.7990 \\
Inner Mongolia & 0.9473 & 0.7124 & 0.9508 & 0.7861 & Hainan & 1.0000 & 1.0000 & 1.0000 & 1.0000 \\
Liaoning & 0.8397 & 0.7955 & 1.0000 & 0.8365 & Chongqing & 0.7965 & 0.7762 & 0.9794 & 0.8152 \\
Jilin & 1.0000 & 0.8849 & 1.0000 & 1.0000 & Sichuan & 0.8218 & 0.6871 & 0.8656 & 0.8002 \\
Heilongjiang & 0.9827 & 0.8719 & 1.0000 & 1.0000 & Guizhou & 0.6954 & 0.5925 & 0.9233 & 0.7952 \\
Shanghai & 1.0000 & 1.0000 & 1.0000 & 1.0000 & Yunnan & 0.7132 & 0.5673 & 0.8414 & 0.7277 \\
Jiangsu & 1.0000 & 1.0000 & 1.0000 & 1.0000 & Tibet & 0.7407 & 0.7106 & 1.0000 & 1.0000 \\
Zhejiang & 1.0000 & 1.0000 & 1.0000 & 1.0000 & Shaanxi & 0.8161 & 0.7058 & 0.8341 & 0.7843 \\
Anhui & 0.8208 & 0.6781 & 0.8414 & 0.7552 & Gansu & 0.7641 & 0.6791 & 1.0000 & 1.0000 \\
Fujian & 1.0000 & 1.0000 & 1.0000 & 1.0000 & Qinghai & 0.7981 & 0.7724 & 1.0000 & 1.0000 \\
Jiangxi & 0.8268 & 0.6903 & 0.8796 & 0.7877 & Ningxia & 1.0000 & 1.0000 & 1.0000 & 1.0000 \\
Shandong & 1.0000 & 1.0000 & 1.0000 & 1.0000 & Xinjiang & 0.7037 & 0.5896 & 0.9762 & 0.8273 \\
Henan & 0.8470 & 0.7608 & 0.8854 & 0.8212 & & & & & \\
\hline
\end{tabular}

Then the results of the improved input indices of each province and the total improvement ranking from 2013 to 2017 in the input-oriented model are obtained using similar method to that for 2017 . The relevant results are shown in Table 4. 
The projection improvement of the efficient provinces are all zero, so the relevant results of these provinces are not given in Table 4.

From the results of Table 2 and 4, it can be found that there is a certain difference between the results of the overall improvement in 2017 and from 2013 to 2017, which indicates that the pollution process in the eco-environment of each province was changing. Liaoning saw the biggest change, and Inner Mongolia and Hebei Province had the greatest difficulty in eco-environment management.

In order to more visually reflect the projection improvement difficulty coefficients of the comprehensive evaluation on the environment in different provinces, the relevant hotspot distribution map is drawn according to the size of the projection improvement quantity of the provinces in Figure 6. The darker the colour, the worse the comprehensive evaluation effect of the environment, and the higher the difficulty coefficient of projection improvement.

From Figure 6, it is easy to find that the provinces with the highest comprehensive efficiency of eco-environment from 2013 to 2017 based on the generalized DEA are located in the economically developed coastal areas, and that the most economically backward four regions also have high efficiency. The efficiency of environmental status management in northern and central provinces is relatively low, and the difficulty coefficients are relatively large. Inner Mongolia, Shanxi and Xinjiang take coal and other energy as the main driving force for development, while Hebei Province mainly relies on iron and steel for development. Their efficiency is poor and it may be difficult to complete rapid projection improvement within a short time.

Table 4. Projection improvement information of Chinese provinces in CCR for the average input-output data from 2013 to 2017 based on the generalized input-oriented DEA method

\begin{tabular}{c|c|c|c|c|c|c|c|c|c|c}
\hline Province & $\mathbf{I 1}$ & $\mathbf{I 2}$ & $\mathbf{I 3}$ & $\mathbf{I 4}$ & $\mathbf{I 5}$ & $\mathbf{I 6}$ & $\mathbf{I 7}$ & $\mathbf{I 8}$ & $\mathbf{I 9}$ & $\begin{array}{c}\text { Total } \\
\text { improvement }\end{array}$ \\
\hline Inner Mongolia & $16.63 \%$ & $15.02 \%$ & $13.27 \%$ & $4.10 \%$ & $7.79 \%$ & $13.81 \%$ & $3.18 \%$ & $13.53 \%$ & $10.57 \%$ & $97.90 \%$ \\
Shanxi & $19.25 \%$ & $16.13 \%$ & $19.14 \%$ & $4.17 \%$ & $1.97 \%$ & $10.98 \%$ & $3.13 \%$ & $10.13 \%$ & $7.08 \%$ & $91.98 \%$ \\
Xinjiang & $14.22 \%$ & $13.30 \%$ & $13.47 \%$ & $3.68 \%$ & $2.16 \%$ & $11.57 \%$ & $4.74 \%$ & $11.76 \%$ & $13.52 \%$ & $88.42 \%$ \\
Hebei & $13.58 \%$ & $16.58 \%$ & $17.47 \%$ & $5.14 \%$ & $1.58 \%$ & $9.67 \%$ & $3.46 \%$ & $8.63 \%$ & $9.60 \%$ & $85.71 \%$ \\
Yunnan & $9.55 \%$ & $6.96 \%$ & $5.95 \%$ & $4.67 \%$ & $8.23 \%$ & $5.17 \%$ & $5.06 \%$ & $17.00 \%$ & $18.17 \%$ & $80.76 \%$ \\
Jiangxi & $6.06 \%$ & $6.12 \%$ & $5.69 \%$ & $6.39 \%$ & $11.63 \%$ & $11.49 \%$ & $3.54 \%$ & $13.52 \%$ & $11.59 \%$ & $76.03 \%$ \\
Guizhou & $15.69 \%$ & $8.26 \%$ & $6.40 \%$ & $2.86 \%$ & $1.58 \%$ & $5.03 \%$ & $4.00 \%$ & $17.31 \%$ & $13.78 \%$ & $74.91 \%$ \\
Hunan & $3.45 \%$ & $3.21 \%$ & $2.72 \%$ & $7.37 \%$ & $16.30 \%$ & $9.79 \%$ & $4.29 \%$ & $12.24 \%$ & $12.38 \%$ & $71.75 \%$ \\
Anhui & $5.23 \%$ & $7.27 \%$ & $5.53 \%$ & $4.63 \%$ & $2.17 \%$ & $7.63 \%$ & $4.61 \%$ & $15.95 \%$ & $14.59 \%$ & $67.61 \%$ \\
Liaoning & $11.65 \%$ & $11.03 \%$ & $12.02 \%$ & $3.23 \%$ & $1.01 \%$ & $5.81 \%$ & $4.57 \%$ & $8.70 \%$ & $8.99 \%$ & $67.01 \%$ \\
Sichuan & $5.58 \%$ & $4.36 \%$ & $3.27 \%$ & $4.54 \%$ & $2.11 \%$ & $5.01 \%$ & $6.52 \%$ & $14.54 \%$ & $20.32 \%$ & $66.25 \%$ \\
Shaanxi & $8.21 \%$ & $7.37 \%$ & $6.88 \%$ & $3.31 \%$ & $2.20 \%$ & $7.79 \%$ & $4.05 \%$ & $13.89 \%$ & $10.97 \%$ & $64.67 \%$ \\
Henan & $5.12 \%$ & $6.42 \%$ & $3.82 \%$ & $6.51 \%$ & $2.55 \%$ & $8.96 \%$ & $5.19 \%$ & $10.86 \%$ & $14.16 \%$ & $63.59 \%$ \\
Gansu & $8.73 \%$ & $6.41 \%$ & $5.67 \%$ & $3.53 \%$ & $9.33 \%$ & $7.96 \%$ & $3.03 \%$ & $4.59 \%$ & $9.52 \%$ & $58.77 \%$ \\
Hubei & $2.98 \%$ & $2.97 \%$ & $2.47 \%$ & $4.95 \%$ & $3.37 \%$ & $8.71 \%$ & $4.63 \%$ & $9.54 \%$ & $11.22 \%$ & $50.84 \%$ \\
Guangxi & $3.42 \%$ & $3.43 \%$ & $3.13 \%$ & $3.24 \%$ & $2.99 \%$ & $2.88 \%$ & $3.65 \%$ & $15.01 \%$ & $10.95 \%$ & $48.70 \%$ \\
Heilongjiang & $8.05 \%$ & $9.88 \%$ & $10.52 \%$ & $1.33 \%$ & $0.56 \%$ & $1.64 \%$ & $1.94 \%$ & $2.11 \%$ & $8.87 \%$ & $44.90 \%$ \\
Chongqing & $4.21 \%$ & $2.84 \%$ & $2.17 \%$ & $2.34 \%$ & $0.94 \%$ & $2.97 \%$ & $2.89 \%$ & $11.01 \%$ & $7.23 \%$ & $36.60 \%$ \\
Jilin & $4.86 \%$ & $5.75 \%$ & $5.14 \%$ & $2.82 \%$ & $1.49 \%$ & $5.50 \%$ & $1.63 \%$ & $2.09 \%$ & $4.72 \%$ & $34.00 \%$ \\
Tibet & $0.96 \%$ & $0.96 \%$ & $0.96 \%$ & $0.96 \%$ & $0.97 \%$ & $0.96 \%$ & $2.23 \%$ & $17.88 \%$ & $3.44 \%$ & $29.32 \%$ \\
Qinghai & $1.44 \%$ & $1.07 \%$ & $1.66 \%$ & $1.78 \%$ & $2.16 \%$ & $4.21 \%$ & $1.33 \%$ & $8.52 \%$ & $2.89 \%$ & $25.06 \%$ \\
\hline
\end{tabular}




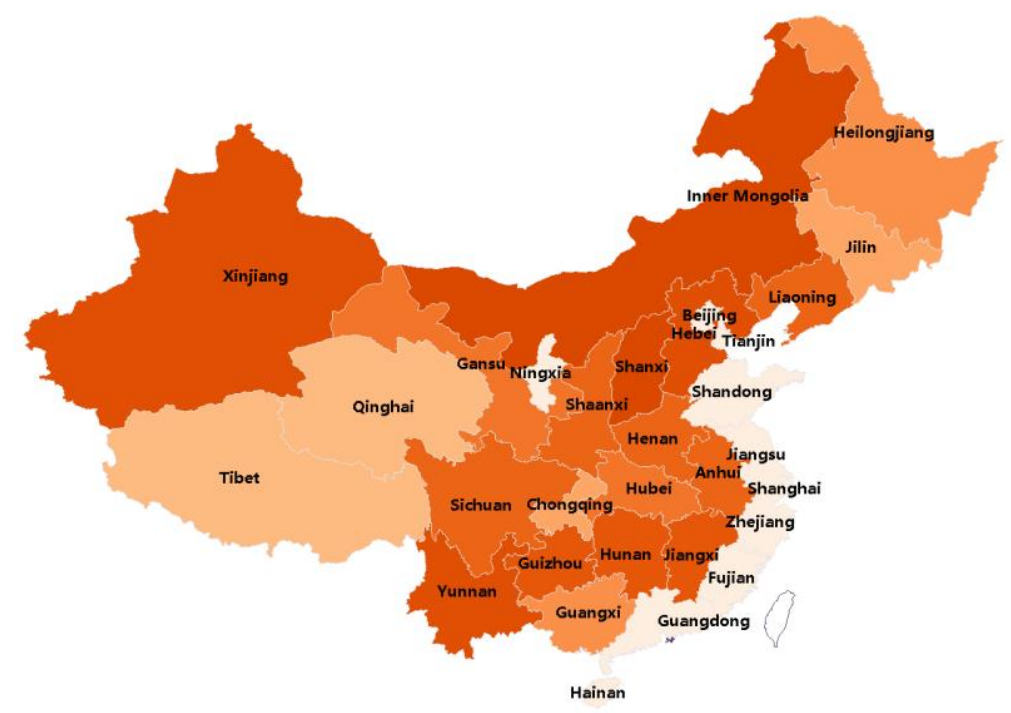

Figure 6. Hotspot map of difficulty coefficient for projection improvement of environmental status in China from 2013 to 2017

\section{Improvement, projection and importance information before and after the synthesis of various indices}

Although the improvement of eco-environmental inputs in each province from 2013 to 2017 is proposed above, it is unrealistic to make the improvement according to this model. Managers need more learning to complete the gradual improvement. Muren et al. (2013) provided a DEA method based on the partial ordered set theory, which can give the complex partial ordered relations among DMUs and provide information for DMUs, such as improvement, projection and importance.

The partial ordered relations among Chinese provinces are shown in Figures 7 and 8 . It is easy to find that the original status which involves less partial ordered relations among provinces has turned into one with more partial ordered relation after index synthesis.

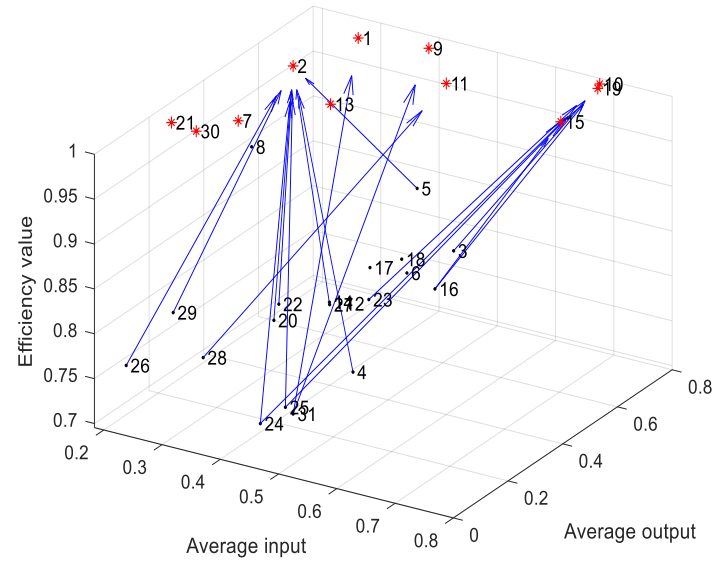

Figure 7. Partial ordered relations among the provinces in the CCR model before index synthesis 


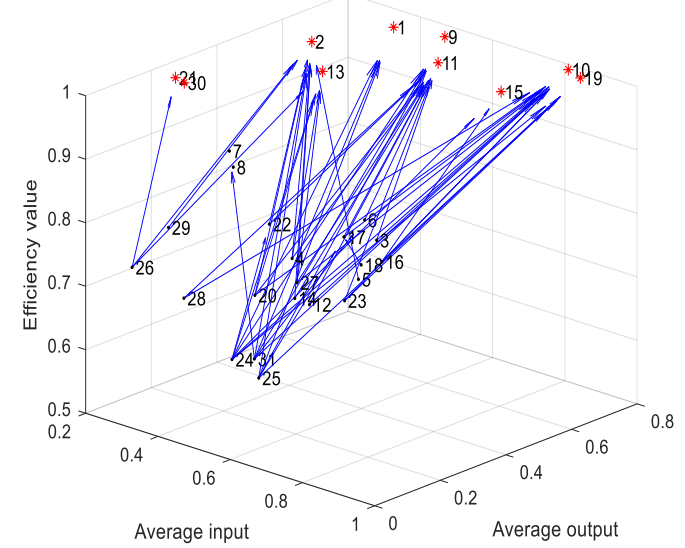

Figure 8. Partial ordered relations among the provinces in the CCR model after index synthesis

In Table 5, we proposed the ways of improvements and projections and the importance of learning for different provinces in the CCR model. The inefficient provinces can improve their input data according to the partial ordered relations between efficient provinces. For example, Inner Mongolia can improve its efficiency by learning from Tianjin.

Table 5. Improvement and projection methods and learning importance of different provinces in the CCR model

\begin{tabular}{|c|c|c|c|c|c|c|c|}
\hline \multirow[b]{2}{*}{ Number } & \multirow[b]{2}{*}{ Provinces } & \multicolumn{3}{|c|}{ Original indices in the CCR model } & \multicolumn{3}{|c|}{ Synthesized Indices in the CCR model } \\
\hline & & $\begin{array}{c}\text { Improved } \\
\text { benchmark }\end{array}$ & $\begin{array}{c}\text { Projection } \\
\text { benchmark }\end{array}$ & $\begin{array}{c}\text { Learning } \\
\text { importance }\end{array}$ & $\begin{array}{c}\text { Improved } \\
\text { benchmark }\end{array}$ & Projection benchmark & $\begin{array}{l}\text { Learning } \\
\text { importance }\end{array}$ \\
\hline 1 & Beijing & --- & --- & 1 & --- & --- & 3 \\
\hline 2 & Tianjin & --- & --- & 9 & --- & --- & 11 \\
\hline 3 & Hebei & --- & 10 & 0 & --- & 1,11 & 0 \\
\hline 4 & Shanxi & --- & 2 & 0 & --- & $2,11,13$ & 0 \\
\hline 5 & Inner Mongolia & --- & 2 & 0 & --- & 2 & 0 \\
\hline 6 & Liaoning & --- & --- & 0 & --- & 11 & 1 \\
\hline 7 & Jilin & --- & --- & 0 & --- & --- & 1 \\
\hline 8 & Heilongjiang & --- & --- & 0 & --- & --- & 0 \\
\hline 9 & Shanghai & --- & --- & 1 & --- & --- & 3 \\
\hline 10 & Jiangsu & --- & --- & 5 & --- & --- & 12 \\
\hline 11 & Zhejiang & --- & --- & 1 & --- & --- & 15 \\
\hline 12 & Anhui & --- & --- & 0 & --- & 1,11 & 0 \\
\hline 13 & Fujian & --- & --- & 0 & --- & --- & 5 \\
\hline 14 & Jiangxi & --- & --- & 0 & --- & 2,11 & 0 \\
\hline 15 & Shandong & --- & --- & 1 & --- & --- & 2 \\
\hline 16 & Henan & --- & 10,15 & 0 & --- & $1,15,19$ & 0 \\
\hline 17 & Hubei & --- & --- & 0 & --- & 1,11 & 2 \\
\hline 18 & Hunan & --- & --- & 0 & 17 & 1,11 & 0 \\
\hline 19 & Guangdong & --- & --- & 0 & --- & --- & 4 \\
\hline 20 & Guangxi & --- & 2 & 0 & --- & $2,1,11,13$ & 0 \\
\hline 21 & Hainan & --- & --- & 0 & --- & --- & 1 \\
\hline 22 & Chongqing & --- & 2 & 0 & --- & 2,11 & 1 \\
\hline 23 & Sichuan & --- & 10 & 0 & --- & $1,11,19$ & 0 \\
\hline 24 & Guizhou & --- & 2,10 & 0 & 22 & $1,2,9,1,11,13,15,19$ & 0 \\
\hline 25 & Yunnan & --- & 2,10 & 0 & 17 & $1,2,9,1,11,19$ & 0 \\
\hline 26 & Tibet & --- & 2 & 0 & --- & $2,13,21$ & 0 \\
\hline 27 & Shaanxi & --- & 2 & 0 & --- & $2,1,11,13$ & 0 \\
\hline 28 & Gansu & --- & 11 & 0 & --- & 1,11 & 0 \\
\hline 29 & Qinghai & --- & 2 & 0 & --- & 2 & 0 \\
\hline 30 & Ningxia & --- & --- & 0 & --- & --- & 0 \\
\hline 31 & Xinjiang & --- & 1,9 & 0 & 6,7 & $1,2,9,1,11$ & 0 \\
\hline
\end{tabular}


With the relevant information provided in Figure 8 and Table 5, each province can determine its own improvement benchmark and projection benchmark. At the same time, the state should give certain rewards to those provinces with higher performance, and impose corresponding punishments on those that perform poorly so that they will take scientific and sustainable eco-environmental governance strategies as soon as possible

\section{Conclusions}

The synthesis and projection theory of input-output indices of DMUs based on generalized DEA provides a new basis for ranking and improvement of DMUs. The improved method is highly applicable in the horizontal and vertical evaluation and improvement of enterprises or government departments with time series data. In this paper, taking the evaluation on the interaction between eco-environment and economy among Chinese provinces as an example, through reasonable index selection and processing, an evaluation index system with strong logical relationships is constructed, and the evaluation of provinces is carried out with the generalized DEA model. Relevant data analysis results show that the synthesis of the input-output indices of each province can help further discover the efficiency gaps between the provinces, and also provide the improvement scale and direction of the main pollution sources in the ecoenvironment of each province. Finally, the combination of the index synthesis theory and the partial ordered set theory provides a new basis for the mutual learning among provinces. These basic models and methods further enrich and improve the scientific evaluation on eco-environment, and provide detailed quantitative indices for the protection and governance of eco-environment.

The rationality of index synthesis and projection of DMU is worthy of further study. It will also be of great significance to evaluate the interaction efficiency between ecoenvironment and economic development in China from the time series data of industrial structure of each province. At the same time, these theories and methods proposed in this paper can be extended to the assessment the interaction efficiency between ecoenvironment and economic development in other countries, which will help to formulate rational environmental protection programmes, better protect the earth and safeguard the global climate, and it lay theoretical and practical foundation for the comprehensive, balanced and sustainable development of eco-environment and economy.

Acknowledgements. The authors would like to thank the anonymous reviewers for the useful comments on this work, and the support from, National Natural Science Funds of China (No. 71661025, 71401084), Inner Mongolia Natural Science Foundation (No. 2017JQ02, 2017MS072, 2016MS0705), Inner Mongolia Grassland Talent Project (No. 12000-12102012), China Post-doctoral Fund (No. 2018M631323), and Project of Inner Mongolia Institute of Data Science and Big Data (No. BDY18007).

\section{REFERENCES}

[1] Banker, R. D., Charnes, A., Cooper, W. W. (1984): Some models for estimating technical and scale inefficiencies in data envelopment analysis. - Management Science 30(9): 1078-1092. 
[2] Brown, G. M. (2000): Renewable natural resource management and use without markets. - Journal of Economic Literature 38(4): 875-914.

[3] Chang, Y. T., Park, H. S., Jeong, J. B., Lee, J. W. (2014): Evaluating economic and environmental efficiency of global airlines: a SBM-DEA approach. - Transportation Research Part D Transport \& Environment 27(1): 46-50.

[4] Charnes, A., Cooper, W. W., Rhodes, E. (1978): Measuring the efficiency of decision making units. - European Journal of Operational Research 6(2): 429-444.

[5] Diao, X. D., Zeng, S. X., Tam, C. M., Tam, V. W. Y. (2009): EKC analysis for studying economic growth and environmental quality: a case study in China. - Journal of Cleaner Production 17(5): 541-548.

[6] Färe, R., Grosskopf, S. (1985): A nonparametric cost approach to scale efficiency. Scandinavian Journal of Economics 87(4): 594-604.

[7] Gaspar, J. D. S., Marques, A. C., Fuinhas, J. A. (2017): The traditional energy-growth nexus: A comparison between sustainable development and economic growth approaches. - Ecological Indicators 75: 286-296.

[8] Halkos, G. E., Polemis, M. L. (2018): The impact of economic growth on environmental efficiency of the electricity sector: A hybrid window DEA methodology for the USA. Journal of Environmental Management 211: 334-346.

[9] Jia, Y. P., Liu, R. Z. (2012): Study of the energy and environmental efficiency of the Chinese economy based on a DEA model. - Procedia Environmental Sciences 13(10): 2256-2263.

[10] Lee, S. K., Mogi, G., Hui, K. S. (2013): A fuzzy analytic hierarchy process (AHP)/data envelopment analysis (DEA); hybrid model for efficiently allocating energy $R \& D$ resources: In the case of energy technologies against high oil prices. - Renewable \& Sustainable Energy Reviews 21: 347-355.

[11] Liu, B. Q., Tian, C., Li, Y. Q., Song, H. H., Ma, Z. X. (2018): Research on the effects of urbanization on carbon emissions efficiency of urban agglomerations in China. - Journal of Cleaner Production 197(1): 1374-1381.

[12] Ma, X., Raheel, M., Xue, T. T., Wang, J. D. (2017): Measurement of China's regional eco-economy input efficiency and its temporal-spatial evolution. - China Population Resources and Environment 11: 13-23.

[13] Ma, Z. X. (2002): Frontier that formed by some sample units and its applying. - Journal of Inner Mongolia University (Natural Science Edition) 33: 606-610.

[14] Ma, Z. X. (2003): Frontier that formed by some sample units and its applying. - Systems Engineering-Theory and Practice 23: 32-27.

[15] Ma, Z. X. (2012): DEA model with generalized reference set and its properties. Systems Engineering and Electronics 34: 709-714.

[16] Ma, Z. X., Cao, L., Bao, S. Q. G. W. (2018): A resource optimized allocation method of multi-level complex system. - Systems Engineering-Theory \& Practice 38(7): 18021818.

[17] Mavi, R. K., Saen, R. F., Goh, M. (2018): Joint analysis of eco-efficiency and ecoinnovation with common weights in two-stage network DEA: a big data approach. Technological Forecasting and Social Change 144: 553-562.

[18] Mittler, D., Knirsch, J. (2007): Improved market access at the expense of the environment? The environmental risks of the NAMA negotiations at the WTO. Environmental Politics 16(1): 113-123.

[19] Moutinho, V., Madaleno, M., Robaina, M. (2017): The economic and environmental efficiency assessment in EU cross-country: Evidence from DEA and quantile regression approach. - Ecological Indicators 78: 85-97.

[20] Moutinho, V., Madaleno, M., Robaina, M., Villar, J. (2018): Advanced scoring method of eco-efficiency in European cities. - Environmental Science and Pollution Research 25(2): $1637-1654$. 
[21] Muren, Ma, Z. X., Wei, C. (2013): Data envelopment analysis based on partial ordered set theory. - Systems Engineering and Electronic Technology 35(2): 350-356.

[22] Seiford, L. M., Thrall, R. M. (1990): Recent development in DEA. The mathematical programming approach to frontier analysis. - Journal of Economics 46(1-2): 7-38.

[23] Song, M., Peng, J., Wang, J., Zhao, J. (2018): Environmental efficiency and economic growth of China: a ray slack-based model analysis. - European Journal of Operational Research 269(1): 51-63.

[24] Wang, P., Wu, J. (2014): Environment and economic performance evaluation of 30 provinces and municipalities in China based on a two-stage multiplier DEA approach. International Journal of Information \& Decision Sciences 6(2): 182-192.

[25] Yang, Q. S., Zhang, Y., Li, Y. J. (2012): Research on environmental efficiency evaluation of urban agglomerations in northeast China based on DEA model. - Economic Geography 32(9): 51-60.

[26] Zhou, Y. (2015): State power and environmental initiatives in China: analyzing China's green building program through an ecological modernization perspective. - Geoforum 61: $1-12$. 